\title{
Prevalence of impaired glucose tolerance and insulin resistance among obese children and adolescents
}

This article was published in the following Dove Press journal:

Therapeutics and Clinical Risk Management

16 July 2010

Number of times this article has been viewed

\author{
Robabeh Ghergherechi' \\ Ali Tabrizi ${ }^{2}$ \\ 'Department of Pediatrics \\ Endocrinology, Tabriz University \\ of Medical Sciences, Tabriz, Iran; \\ ${ }^{2}$ Students' Research Committee, \\ Tabriz University of Medical Sciences, \\ Tabriz, Iran
}

Purpose: Obesity is one of the most important nutritional disorders in the world which has an obvious relationship with the incidence of metabolic diseases. Obesity prevalence has increased among children and adolescents during recent decades, leading to a rise in Type 2 diabetes mellitus (DM II) prevalence in these two age brackets. Hence, the aim of this study was to assess impaired glucose tolerance and insulin resistance, and gather metabolic findings in obese children and adolescents.

Methods and materials: We studied 110 obese children and adolescents (body mass index $>95$ th percentile for age and gender) 4-18 years of age referred to the endocrine clinic of the Children's Hospital at Tabriz University in a descriptive cross-sectional study. Fasting glucose, insulin, and lipid profile in all subjects were determined. Oral glucose tolerance test after eating $75 \mathrm{~g} / \mathrm{kg}$ glucose was performed. Homeostatic model assessment was used to estimate insulin resistance.

Results: Impaired glucose tolerance and insulin resistance prevalence in 68 obese adolescents was $14.7 \%$ and $31.8 \%$, respectively. Impaired glucose tolerance and insulin resistance was not seen in $23.8 \%$ of 42 obese children. No case of DM II was seen. There was a significant statistical difference in glucose $(P=0.003)$ and insulin $(P<0.001)$ level at minute 120 in individuals with impaired glucose tolerance compared to obese children and adolescents without impaired glucose tolerance. Rate of insulin resistance in patients with impaired glucose tolerance was greater and had a significant statistical difference $(P=0.03)$.

Conclusion: Obesity has a close relationship with increased risk of impaired glucose tolerance and insulin resistance in children and adolescents. Oral glucose tolerance test, unlike fasting glucose test, is a benefit test to predict impaired glucose tolerance. With prompt identification and treatment of obese children with impaired glucose tolerance, we can prevent it from progression towards DM II.

Keywords: impaired glucose tolerance, insulin resistance, obesity

\section{Introduction}

Prevalence of obesity among children and adolescents has been drastically increasing during the last two decades and age of onset of Type 2 diabetes mellitus (DM II) symptoms is depreciating. ${ }^{1,2}$ Prevalence of obesity in many parts of the world has doubled during the last two decades and approximately 22 million children under five years are overweight. ${ }^{3}$ Obesity increases the risk of insulin resistance in childhood and mortality due to cardiovascular diseases in adulthood. ${ }^{4}$ Several factors including obesity, dyslipidemia, and hypertension in children and adolescents have a significant role in elevating the risk of insulin resistance. ${ }^{5}$
Assistant Professor of Pediatric

Endocrinology, Department of Pediatrics, Tabriz University of Medical Sciences,

Tabriz, Iran

Tel +98914413 II 49

Fax +984113355333

Email ghergherehchir@tbzmed.ac.ir 
Progressing from glucose tolerance into DM II in adulthood usually has a mediating phase which occurs by an alteration in metabolism of glucose and is declared as impaired glucose tolerance or the phase before diabetes. ${ }^{6,7}$

High prevalence of impaired glucose tolerance among obese children and adolescents has been reported in many descriptive cross-sectional studies, indicating the correlation between obesity and severe resistance to insulin, impaired glucose tolerance, dysfunction of pancreatic $\beta$-cells and change of abdominal fat distribution. ${ }^{8}$

Obesity prevalence in Iran has also been increasing during recent decades; in adolescents aged $11-17$ years, $22.5 \%$ had a body mass index (BMI) in 95 th percentile and $26.6 \%$ were suffering from metabolic syndrome. ${ }^{9}$ Also, many Iranian children are suffering from synchronous metabolic syndrome as shown in one study where $42.5 \%$ of obese children had synchronous metabolic syndrome. ${ }^{10}$

Obesity and insulin resistance play a crucial role in pathogenesis of metabolic syndrome.

According to increasing prevalence of obesity and its complications in children and adolescents, our aim is to determine the prevalence of impaired glucose tolerance and insulin resistance among obese children and adolescents.

\section{Methods}

In a retrospective randomized study, 110 children and adolescents who were referred for medical assessment of obesity in a pediatric endocrinology clinic were studied from June 2006 through to September 2008. Inclusion criteria were those aged 4-18 years with a body mass index (BMI) exceeding the 95th percentile for their age and sex. Individuals who were receiving drugs which could influence carbohydrate and lipid metabolisms, or suffering from diabetes and/or familial hyperlipidemia were excluded from the study.

Clinical examination, blood pressure, height (by a wall tape measure with accuracy of $0.1 \mathrm{~cm}$ ) and weight (by a SECA weighing machine [SECA Medical, Massachusetts, USA] with accuracy of $0.5 \mathrm{~kg}$ ) measurements, and BMI $\left(\mathrm{kg} / \mathrm{m}^{2}\right)$ were obtained after receiving informed and written consent from parents involved. Fasting blood sampling was executed after a $12 \mathrm{hr}$ fasting period to measure glucose, insulin, and lipid profile.

We assessed impaired glucose tolerance after eating $75 \mathrm{~g} / \mathrm{kg}$ up to a maximum of $750 \mathrm{~g}$ glucose in $250 \mathrm{cc}$ water and measured blood glucose and insulin level at min 0,30, 60 , and 120 . Glucose was measured by the glucose oxidase method and insulin was measured with a radioimmunoassay. Insulin resistance rate using homeostasis model assessment (HOMA) index was calculated by the following formula: HOMA index $=$ [fasting insulin $(\mathrm{mU} / \mathrm{mL}) \times$ fasting glucose $(\mathrm{mmol} / \mathrm{L})] / 22.5 .{ }^{11}$ Lower HOMA index values $(<4)$ indicated higher insulin sensitivity, whereas higher values $(>4)$ indicated lower insulin sensitivity. Impaired glucose tolerance was defined as $2 \mathrm{hr}$ plasma glucose level of 140-200 mg/dL. DM II was defined as a fasting glucose level over $126 \mathrm{mg} / \mathrm{dL}$ or $2 \mathrm{hr}$ postprandial glucose over $200 \mathrm{mg} / \mathrm{dL} .{ }^{12}$

\section{Statistical methods}

Statistical analysis was done using the statistical package SPSS 16 (IBM, New York, USA). The data is shown as Mean \pm SD with $95 \%$ confidence interval. Normality of the distribution was checked for each variable (one sample Kolmogorov-Smirnov test). Mann-Whitney $U$ statistical was used to check the difference in means of laboratory findings between the two groups including adolescents with and without insulin resistance. Repeat measure test was used for means of glucose and insulin changes at different times. Chi-square and Fisher's exact test were used to determine statistical difference in qualitative variables. Association between two variables was determined by Pearson correlation. $P$ value less than 0.05 was considered statistically significant.

\section{Results}

Of the 110 obese children and adolescents conducted in this study, 69 were female and 41 were male. The mean age was $10.9 \pm 3$ years; 42 (38.2\%) were under 10 years and 68 $(61.8 \%)$ were over 10 years. Total impaired glucose tolerance prevalence rate was $14.7 \%$ in adolescents, which was not seen among children, and total prevalence of insulin resistance was $31.8 \%$ in adolescents and $23.8 \%$ in children. There was no significant difference in the prevalence of impaired glucose tolerance between male and female adolescents $(8.7 \%$ female and $9.8 \%$ male). Similarly, there was no significant difference in insulin resistance between males and females (36.7\%, 26.1\%). DM II was not seen among obese children and adolescents. Table 1 indicates the characteristics of patients studied in this study based upon age classification.

There was no significant difference between children and adolescents, with and without impaired glucose tolerance, at $\min 0$; however, there was a significant statistical difference in glucose level $(101.9 \pm 17.2 \mathrm{mg} / \mathrm{dL}$ versus $145.5 \pm 25 \mathrm{mg} / \mathrm{dL})$ and insulin level $(62.02 \pm 69.7 \mathrm{ng} / \mathrm{dL}$ versus $208.3 \pm 262 \mathrm{ng} / \mathrm{dL}$ ) at min 120 between the two groups $(P=0.003, P<0.001)$. 
Table I Characteristics of patients studied, based upon age classification

\begin{tabular}{lll}
\hline Variables & Children $(\mathbf{n}=\mathbf{4 2})$ & Adolescents $(\mathbf{n}=\mathbf{6 8})$ \\
\hline Gender & & \\
Male & $8(19 \%)$ & $33(48.5 \%)$ \\
Female & $34(81 \%)$ & $35(51.5 \%)$ \\
Resistance to insulin & $10(23.8 \%)$ & $21(31.8 \%)$ \\
$($ HOMA $>4)$ & & $10(14.7 \%)$ \\
Impaired glucose & - & \\
tolerance & & \\
\hline
\end{tabular}

Table 2 shows the measured and metabolic laboratorial indices in obese adolescents. According to this table, plasma level of very-low-density lipoprotein (VLDL) was significantly different between the two groups of adolescents. In the other lipid profile, there was no significant difference. There were 66 insulin resistant individuals (60\%) and HOMA index values for these cases were over four, which had a significant statistical difference with other obese children and adolescents $(P=0.03)$.

Assessment of glucose and insulin change spectrum at different times (Figures 1 and 2) shows a significant difference in patients with impaired glucose tolerance detected by glucose tolerance test $(P<0.001)$. Among individuals resistant to insulin $(\mathrm{n}=31)$ there was a significant relationship in VLDL levels $(P=0.008$ and $\mathrm{r}=-0.4)$ and triglyceride levels $(P=0.01$ and $\mathrm{r}=0.4)$. There was not a significant correlation between systolic and diastolic blood pressure and resistance to insulin based upon HOMA indices.

\section{Discussion}

Obesity, together with environmental and genetic factors, leads to progression of insulin resistance phase to DM II and failure of pancreatic $\beta$-cells. ${ }^{13}$ Obese children and adolescents with impaired glucose tolerance are predisposed to being high risk for DM II in the future after undergoing a mediating period, and oral glucose tolerance test can be a predictor for impaired glucose tolerance. ${ }^{14}$

In one study there was a close relationship in $18 \%$ of obese Spanish children suffering from metabolic syndrome with insulin resistance rate. ${ }^{15}$ In another study, a high prevalence of impaired glucose tolerance was seen among obese children and adolescents $-25 \%$ of obese children aged $4-10$ years and $11 \%$ of adolescents over 11 years. ${ }^{6}$ In a study conducted by Viner et al $11 \%$ of obese children and adolescents had impaired glucose tolerance, and DM II was a rare condition. ${ }^{16}$ A study by Gallardo et al revealed a carbohydrate metabolism disorder in $3.8 \%$ of obese children and fasting glucose level in most of these individuals, though impaired glucose tolerance was normal. Hence, this measurement was not useful for screening of patients. ${ }^{17}$

A study by Tresaco et al estimated that the prevalence of impaired glucose tolerance among obese children and adolescents had a meaningful difference with other patients. ${ }^{18}$ Similarly in our study, prevalence of impaired glucose tolerance among obese children and adolescents was outstanding and fasting glucose levels in patients did not have meaningful difference, but min 120 glucose level was useful in the diagnosis of children and adolescents with carbohydrate metabolism disorders. There is a direct relationship between insulin resistance and DM II in obese children and adolescents. ${ }^{12}$

Insulin resistance prevalence, based upon descriptive studies, is higher in patients with impaired glucose tolerance compared to other children and adolescents in the same age group. Insulin resistance incidence may have a relationship with obesity like that seen in adults, and central obesity is a determinant for hyperinsulinemia. ${ }^{19}$ Although there is a meaningful difference between obese individuals with impaired glucose tolerance and others based upon the

Table 2 Metabolic and laboratory indices measured in obese adolescents (mean \pm SD)

\begin{tabular}{|c|c|c|c|}
\hline Variables & $\begin{array}{l}\text { Without insulin } \\
\text { resistance }\end{array}$ & $\begin{array}{l}\text { With insulin } \\
\text { resistance }\end{array}$ & P-value \\
\hline Glucose level min 0 (mg/dL) & $115.5 \pm 31.6$ & $136.94 \pm 39.9$ & 0.6 \\
\hline Glucose level min 120 (mg/dL) & $105.05 \pm 22.3$ & $150.5 \pm 25$ & 0.002 \\
\hline Insulin level in $\min 0(\mathrm{ng} / \mathrm{dL})$ & $10.6 \pm 3.8$ & $25.6 \pm 8.9$ & 0.6 \\
\hline Insulin level in min I20 (ng/dL) & $50.2 \pm 51.8$ & $179.9 \pm 138.6$ & $<0.001$ \\
\hline Triglyceride (mg/dL) & $124.5 \pm 68.7$ & $156.2 \pm 119.5$ & 0.1 \\
\hline Cholesterol (mg/dL) & $178.7 \pm 31.9$ & $179.4 \pm 34.2$ & 0.5 \\
\hline $\mathrm{LDL}(\mathrm{mg} / \mathrm{dL})$ & $110.5 \pm 31.3$ & $109.2 \pm 48.6$ & 0.9 \\
\hline VLDL (mg/dL) & $20.8 \pm 12.5$ & $29.4 \pm 24.2$ & 0.03 \\
\hline HDL (mg/dL) & $43.01 \pm 9.2$ & $48.14 \pm 19.7$ & 0.1 \\
\hline Systolic blood pressure (mmHg) & $111.09 \pm 25.5$ & $115.4 \pm 25.6$ & 0.5 \\
\hline Diastolic blood pressure $(\mathrm{mmHg})$ & $72.7 \pm 15.7$ & $68.5 \pm 9.4$ & 0.9 \\
\hline
\end{tabular}




\section{Glucose}

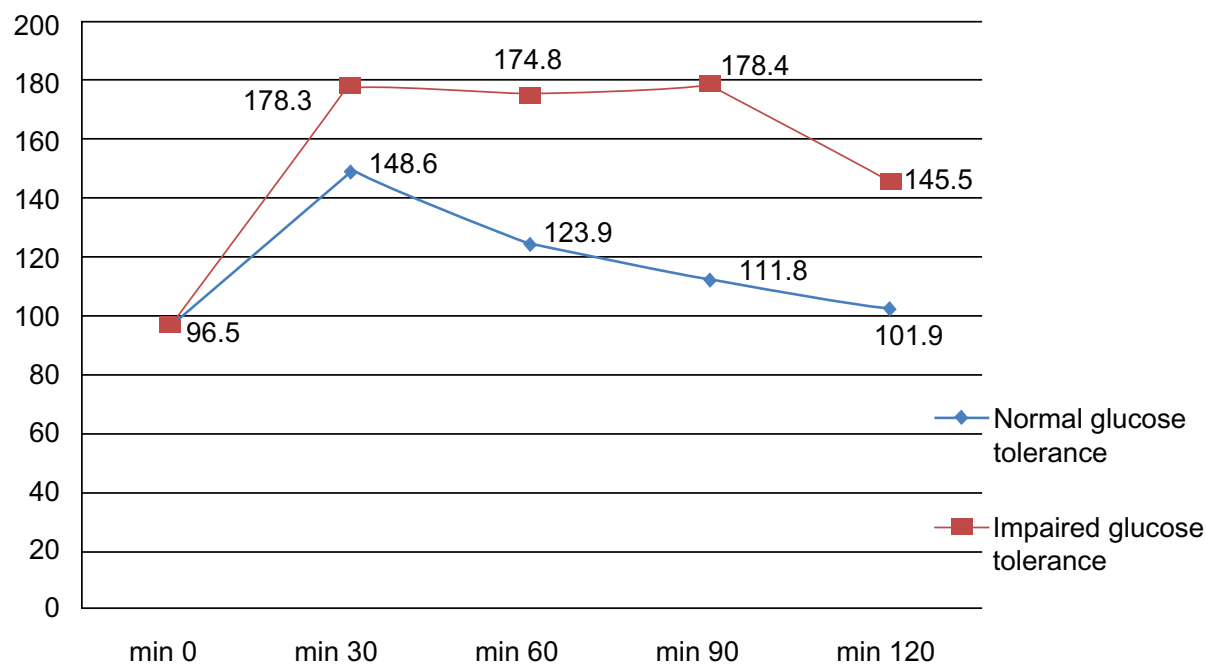

Figure I Glucose response during oral glucose tolerance test in obese children and adolescents.

Tresaco et al study with HOMA indices over four, which is an indicator for insulin resistance, there is not any difference in triglyceride and lipid profile among them. ${ }^{18}$ Similarly in the Moreira et al study, it has been shown that insulin and body fat are very sensitive and specific in predicting insulin resistance among obese children and adolescents. ${ }^{11}$

Our study indicated a high incidence of insulin resistance among obese children and adolescents with impaired glucose tolerance. Based on our study, the prevalence of obesity among children was higher in females than males, but prevalence of obesity in adolescents was very similar between the two. This finding is similar to other pediatric studies. ${ }^{12}$ Prevalence of impaired glucose tolerance and insulin resistance between male and female children and adolescents are similar. In the study by Caceres et al insulin resistance was very common among children and adolescents with obesity. ${ }^{20}$ In our study, as in the Tresaco et al study, lipid profile abnormalities in individuals with insulin resistance is similar to other adolescents with obesity, but only plasma level of VLDL was significantly more than adolescents without insulin resistance. ${ }^{18}$ Despite the fact that there was a negative meaningful correlation between triglyceride level and systolic blood pressure with insulin resistance rate in the Wiegand et al study based on HOMA indices, ${ }^{21}$ our study revealed a negative correlation for triglyceride and VLDL with HOMA indices.

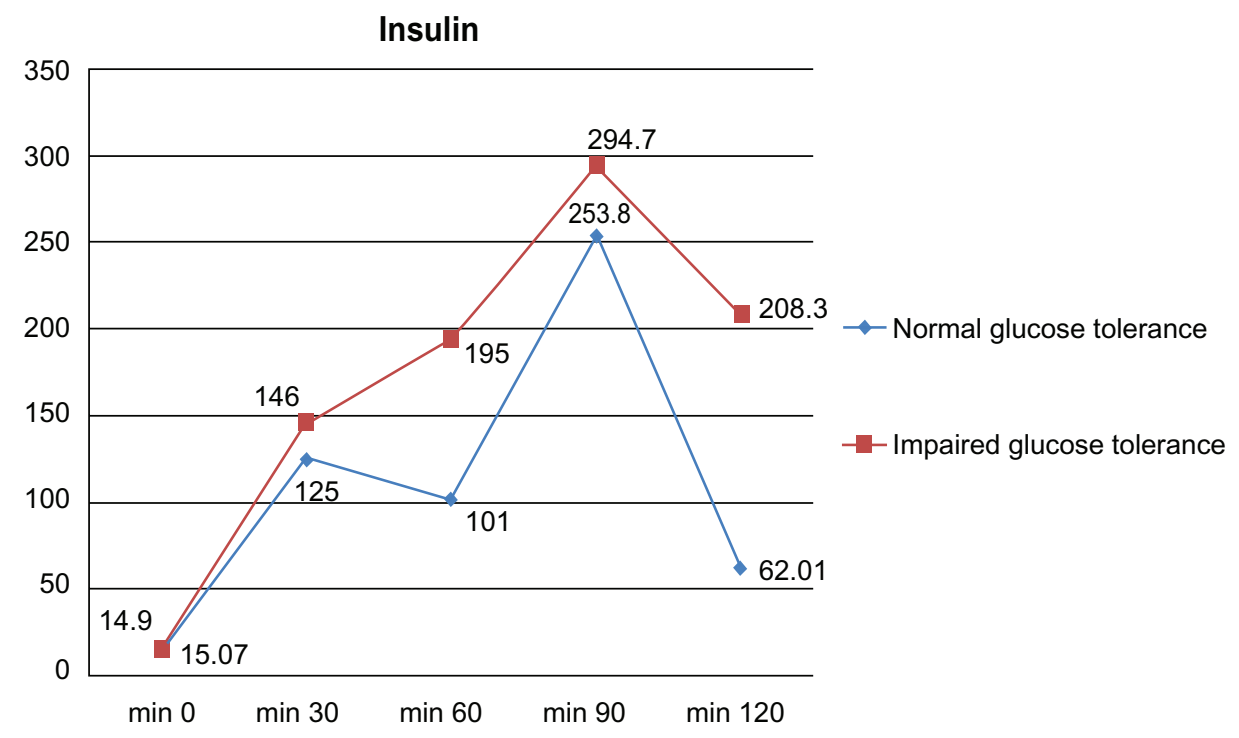

Figure 2 Insulin response during oral glucose tolerance test in obese children and adolescents. 


\section{Conclusion}

Obesity has a close relationship with increased risk of impaired glucose tolerance and insulin resistance in children and adolescents. Oral glucose tolerance test, unlike fasting glucose test, is a benefit test to predict impaired glucose tolerance. With prompt identification and treatment of obese children with impaired glucose tolerance, we can prevent it from progression towards DM II.

\section{Disclosure}

The authors report no conflicts of interest in this work.

\section{References}

1. Troiano RP, Flegal KM, Kuczmarski RJ, Campbell SM, Johnson CL. Overweight prevalence and trends for children and adolescents: the National Health and Nutrition Examination Surveys, 1963 to 1991. Arch Pediatr Adolesc Med. 1995;149(10):1085-1091.

2. Pinhas-Hamiel O, Dolan LM, Daniels SR, Standiford D, Khoury PR, Zeitler P. Increased incidence of non-insulin-dependent diabetes mellitus among adolescents. J Pediatr. 1996;128(5 Pt 1):608-615.

3. Chinn S, Rona RJ. Prevalence and trends in overweight and obesity in three cross sectional studies of British children, 1974-1994. BMJ. 2001; 322:24-26.

4. Freedman DS, Dietz WH, Srinivasan SR, Berenson GS. The relation of overweight to cardiovascular risk factors among children and adolescents: the Bogalusa Heart Study. Pediatrics. 1999;103(6 Pt 1):1175-1182.

5. Young-Hyman D, Schlundt DG, Herman L, de Luca F, Counts D. Evaluation of the insulin resistance syndrome in 5- to 10-year-old overweight/obese African-American children. Diabetes Care. 2001;24(8): 1359-1364.

6. Sinha R, Fisch G, Teague B, et al. Prevalence of impaired glucose tolerance among children and adolescents with marked obesity. $N$ Engl $J$ Med. 2002;346(11):802-810.

7. Csabi G, Torok K, Jeges S, Molnar D. Presence of metabolic cardiovascular syndrome in obese children. Eur J Pediat. 2000;159(1-2):91-94.

8. Weiss R, Dufour S, Taksali SE, et al. Prediabetes in obese youth: a syndrome of impaired glucose tolerance, severe insulin resistance, and altered myocellular and abdominal fat partitioning. Lancet. 2003; 362(9388):951-957.
9. Moayeri H, Rabbani A, Keihanidoust ZT, Bidad K, Anari S. Overweight adolescents: a group at risk for metabolic syndrome (Tehran adolescent obesity study). Arch Iran Med. 2008;11(1):10-15.

10. Kelishadi R, Ardalan G, Gheiratmand R, et al; Caspian Study Group. Thinness, overweight, and obesity in a national sample of Iranian children and adolescents: CASPIAN Study. Child Care Health Dev. 2008;34(1):44-54.

11. Moreira SR, Ferreria AP, Lima RM, et al. Predicting insulin resistance in children: anthropometric and metabolic indicators. J Pediatr (Rio J). 2008;84(1):47-52.

12. Whincup PH, Gilg JA, Papacosta O, et al. Early evidence of ethnic differences in cardiovascular risk: cross sectional comparison of British South Asian and white children. BMJ. 2002;324(7338):635.

13. Reaven GM. Pathophysiology of insulin resistance in human disease Physiol Rev. 1995;75(3):473-486.

14. Weiss R, Taksali SE, Tamborlane WV, Burgert TS, Savoye M, Caprio S. Predictors of changes in glucose tolerance status in obese youth. Diabetes Care. 2005;28(4):902-909.

15. Lopez-Capape M, Alonso M, Colino E, Mustieles C, Corbaton J, Barrio R. Frequency of the metabolic syndrome in obese Spanish pediatric population. Eur J Endocrinol. 2006;155(2):313-319.

16. Viner RM, Sega TY, Lichtarowicz-Krynska E, Hindmarsh P. Prevalence of the insulin resistance syndrome in obesity. Arch Dis Child. 2005; 90(1):10-14

17. Gallardo TV, Avila AA, Unuane MN, Codner E. Fasting glucose versus oral glucose tolerance test for detection of glucose intolerance in obese children. Rev Med Chile. 2006;134(9):1146-1152.

18. Tresaco B, Bueno G, Moreno LA, Garagorri JM, Bueno M. Insulin resistance and impaired glucose tolerance in obese children and adolescents. J Physiol Biochem. 2003;59(3):217-224.

19. Kobayashi K, Amemiya S, Higashida K, et al. Pathogenic factors of glucose intolerance in obese Japanese adolescents with type 2 diabetes. Metabolism. 2000;49(2):186-191.

20. Caceres M, Teran GC, Rodriguez S, Medina M. Prevalence of insulin resistance and its association with metabolic syndrome criteria among Bolivian children and adolescents with obesity. BMC Pediatr. $2008 ; 8: 31$

21. Wiegand S, Maikowski U, Blankenstein O, Biebermann H, Tarnow P, Gruters A. Type 2 diabetes and impaired glucose tolerance in European children and adolescents with obesity - a problem that is no longer restricted to minority groups. Eur J Endocrinol. 2004; 151(2):199-206.
Therapeutics and Clinical Risk Management

\section{Publish your work in this journal}

Therapeutics and Clinical Risk Management is an international, peerreviewed journal of clinical therapeutics and risk management, focusing on concise rapid reporting of clinical studies in all therapeutic areas, outcomes, safety, and programs for the effective, safe, and sustained use of medicines. This journal is indexed on PubMed Central, CAS,

\section{Dovepress}

EMBase, Scopus and the Elsevier Bibliographic databases. The manuscript management system is completely online and includes a very quick and fair peer-review system, which is all easy to use. Visit http://www.dovepress.com/testimonials.php to read real quotes from published authors. 